\title{
LA GUERRA CIVIL Y EL TORNEO A MUERTE EN EL CASTILLO DE LINDABRIDIS DE CALDERÓN DE LA BARCA: ADAPTACIÓN Y REALIZACIÓN ESCÉNICA
}

\author{
Ana Lorena Leija \\ Université Laval \\ [Anuario calderoniano (ISSN: 1888-8046), 2, 2009, pp. 219-230]
}

Dividiré esta exposición en dos partes. La primera reconocerá la relación entre la obra de teatro y la novela en que está basada, es decir, aludirá al proceso de adaptación y reescritura. La segunda propondrá algunas posibilidades de escenificación, tomando en cuenta el horizonte de expectativas contemporáneo.

El castillo de Lindabridis ${ }^{1}$ (ca.1661-1663) pertenece al grupo de obras calderonianas de espectáculo. Comparte además, junto con Hado y divisa de Leonido y Marfisa, El jardín de Falerina o El conde Lucanor, por

${ }^{1}$ Para el estudio y análisis escénico hemos hecho una síntesis del texto electrónico de la edición de Juan Jorge Keil (1830), comparado con la edición de Victoria Torres (1987), de Ángel Valbuena Briones (1959) y la edición facsimilar de Cruickshank y Varey (1973). La numeración de los versos está basada en la edición de Victoria Torres. 
ejemplo, la temática de inspiración caballeresca. Calderón reescribió y adaptó para la escena varios mitos e historias del pasado como se solía hacer en la época. En el caso de El castillo, la novela señalada como el origen de la obra dramática por sus estudiosos y editores (Ángel Valbuena Briones y Victoria Torres), es Espejo de príncipes y caballeros: El caballero del Febo (1555), de Diego Ortúñez de Calahorra.

Según el editor de este texto, Daniel Eisenberg (1975), el Espejo debió de ser muy popular en su época, pues fue uno de los pocos libros de caballería publicados después de 1550 que se reimprimieron. De hecho, ameritó 6 impresiones entre 1555 y 1617, es decir, ya cuando el género había perdido su popularidad. Así también, inspiró una segunda, tercera, cuarta y hasta quinta parte, al parecer, muy menores en calidad al original. El subtítulo "El caballero del Febo» se le añadió después de que la segunda parte había salido haciendo referencia a dicho título en vez del expresado por el autor originalmente, es decir Espejo de príncipes y caballeros. La intención de Ortúñez era escribir una obra distinta, ejemplar y didáctica, no solo otra historia espectacular e increíble, de ahí la elección del vocablo «espejo» en vez del nombre de su protagonista.

Entre los pasajes de la novela y la comedia calderoniana hay una larga lista de diferencias, pero al mismo tiempo podemos encontrar ciertas semejanzas. Una de las similitudes encontradas es la trama desarrollada en torno al triángulo amoroso entre Claridiana, Febo y Lindabridis; a su vez, el mismo triángulo es manipulado de manera distinta en la obra, pues el caballero del Febo no es el conductor de la acción dramática en la comedia, sino los dos personajes femeninos ${ }^{2}$.

${ }^{2}$ Las analogías entre los textos son varias y de distinto tipo: desde el hecho cómico de que Malandrín, el gracioso, al hacer burla de los caballeros andantes al inicio de la segunda jornada se nombra «Malandrín de Trapobana» (que es el nombre de uno de los reyes que apoyan a Trebacio en la novela) hasta que Lindabridis aparezca en un "vehículo insólito", como lo hace en la obra de teatro. Por lo mismo, no coincidimos plenamente con el párrafo en que describe Eisenberg la influencia de la novela en Calderón: «Sirvió el Espejo de príncipes como fuente de una comedia de Calderón - El castillo de Lindabrides - , en la cual, aunque se toma bastantes libertades, presenta el problema central de la obra, el hallar marido para Lindabrides y heredero para el imperio de Tartaria» (t. I, p. XLIX). Si bien es cierto que se ha tomado libertades, pues no coinciden los motivos y los amores de los personajes, en la novela el matrimonio de Lindabridis para heredar el trono de Tartaria es una historia accesoria y no «el problema central de la obra». Al mismo tiempo, la editora de 
Pero regresemos al aspecto bélico que también une a estas dos obras y que nos atañe directamente en esta ocasión. Poco más de cien años separan la novela de Ortúñez de su reescritura calderoniana. La sensibilidad frente a las batallas y los hechos heroicos había cambiado durante el siglo. Además, en el momento de escribir la obra, don Pedro ya había probado los estragos de la guerra en carne propia, defendiendo a España contra ejércitos extranjeros y en las sublevaciones del interior del imperio ${ }^{3}$. Don Emilio Cotarelo y Mori dedicó un largo apartado de su Ensayo sobre la vida y obra de don Pedro Calderón de la Barca a los años militares que vivió el dramaturgo y a los acontecimientos históricos que transformaron el panorama político de esa época ${ }^{4}$. Sin duda la pluma de don Pedro ajustó el tono y las metáforas de sus versos después de haber presenciado escenarios semejantes. En El castillo la violencia se encuentra latente a todo lo largo de la comedia, pero no es llevada a primer plano sino al final, cuando el cierre de la historia depende del duelo a muerte entre los contrincantes.

En la lectura de la obra es fácil percatarse de los varios inicios de duelos de espada y la fuerza brutal del Fauno, cuya sola presencia causa alboroto y desasosiego. Sin embargo, hay una descripción bélica en el monólogo de Lindabridis en la primera jornada, que constituye un punto clave para la construcción dramática de la obra y que podría

la comedia calderoniana, Victoria Torres, nos dice en relación a la novela: «Solo una parte pequeña de los episodios de la novela se reflejará en la comedia, donde, aunque tomándose bastantes libertades, se presenta el problema central de la obra, el hallar marido para Lindabridis y heredero para el imperio de Tartaria» (p. 29). Con casi exactas palabras ambos editores parecen saltar varios de los elementos que comparte la comedia con la novela, quizá porque no leyeron con cuidado las respectivas «otras obras".

${ }^{3}$ Los datos más fidedignos hacen referencia a su participación (1640-1642) como caballero de la orden en la rebelión de Cataluña. Se conoce también la posibilidad de que haya ejercido la vida militar desde 1638 en compañía de su hermano José, en Flandes e Italia.

${ }^{4}$ Cotarelo y Mori, 1924. Así también Evangelina Rodríguez Cuadros (2000), Ángel Valbuena Briones (1959), Ignacio Arellano (1995) y otros biógrafos subrayan este periodo en la vida de don Pedro como un parte aguas, un eje que divide su vida y su producción en dos grandes bloques. Coincide además que las intervenciones militares ocurren justo antes del gran cierre de los teatros por el luto de la reina Isabel de Borbón en 1644 y el príncipe heredero Baltasar Carlos en 1646. 
pasar desapercibido para un lector sin en el entrenamiento de estudio teatral, a saber: la guerra civil.

Nosotros hemos analizado la obra desde un enfoque teatrológico ${ }^{5}$. Más allá del análisis dramático de composición, nuestros criterios e inquietudes van dirigidos a la puesta en escena de la obra. En esta investigación, además, la puesta en escena no es concebida en un sentido universal o atemporal del término, sino que intentamos confrontar la realidad específica de una escenificación que explora el lenguaje tecnológico de Calderón y, como secuela, del teatro barroco español en la segunda mitad del siglo XVII. Recordemos que el concepto de edificio teatral, como lo concebimos hoy en día, nació precisamente a partir de las innovaciones italianas surgidas a finales del siglo XVI y que durante el XVII se expandieron por toda Europa. Tanto las historias de caballería andante como aquellas de la mitología antigua ofrecieron abundante material para concebir los suntuosos espectáculos que se representaban sobre los escenarios a la italiana que presidía la corte madrileña.

Así pues, la secuencia descriptiva de la guerra civil en Tartaria fue escuchada por los espectadores muy al principio de la obra, pues se inicia en el verso 119, como antecedente de la acción escénica. Lindabridis, quien ha llegado con su séquito en un castillo volador, se presenta ante dos caballeros como princesa y posible heredera del trono tártaro, si se lo permite la fortuna. Explicando que en su patria podían gobernar tanto hombres como mujeres, y que era el rey quien designaba al sucesor basado en los méritos de cada hijo o hija ${ }^{6}$; cuenta

${ }^{5}$ Un estudio teatrológico usa los lenguajes y metodologías de distintas ciencias, que permiten percibir al texto como un conjunto de elementos destinados para la escena. La teatrología es una disciplina plural; su campo de estudio abarca tanto la práctica escénica como la tradición textual dramática. Implica la revisión del discurso teatral en toda su envergadura: el espectáculo per se, desde su concepción, pasando por los procesos de producción y materialización, hasta llegar a la recepción. En cuanto a los estudios teóricos de los textos teatrales, el investigador Javier Rubiera comenta: «La complejidad misma del hecho teatral es la que propone que pueda ser abordado desde muy distintas perspectivas metodológicas que suelen privilegiar un aspecto particular sobre el que se insiste, desatendiendo inevitablemente otros» ( $\mathrm{Ru}$ biera, 2005, p. 7).

6 «Es de mi patria heredada / costumbre que no apellide / el pueblo príncipe augusto, / ni le adore, ni se humille/ al hijo mayor del rey; / que solo hereda y preside / el que él en su testamento / a la hora de morirse / deja en sus hijos nom- 
entonces cómo murió su padre sin poder revelar el nombre del heredero al trono entre Meridián, su hermano, y ella. Así, describe el levantamiento en armas de su pueblo dividido en dos grupos:

\author{
dejó en duda la elección \\ $\mathrm{y}$ en bandos parcial y libre \\ la plebe que alborotada \\ por las calles se divide \\ diciendo unos «Meridián \\ viva» y otros «Lindabridis». \\ Llegó la pasión a extremos \\ tales que en guerras civiles \\ la Tartaria ardió. Ya eran \\ las campañas apacibles \\ de Flora selvas de Marte, \\ pues, variados los matices, \\ tal vez murieron claveles \\ los que nacieron jazmines. (vv. 217-230)
}

El vocabulario utilizado para describir las batallas es recurrente en otras obras calderonianas. Recordemos por ejemplo la guerra civil descrita en La vida es sueño (1635), cuando el reino de Basilio se divide en dos, apoyando unos a Astolfo como heredero y otros a Segismundo; o en La hija del aire, II (1664), cuando el apoyo del reino se divide entre Semíramis, disfrazada de Ninias, y Lidoro. La importancia dramática del fragmento de la guerra no debería pasar inadvertida. El caos que reina en Tartaria debe comunicarse al público para que se pueda entender el porqué de toda la acción dramática; además, refuerza la decisión de resolver el conflicto por medio de un solo torneo entre caballeros, en vez de continuar una guerra mortífera y exhaustiva.

En la novela de Ortúñez encontramos varios duelos uno a uno y encuentros bélicos de pequeños grupos que nos sirven de referencia para las escenas de nuestra obra en las que interviene alguna clase de combate. Pero, en el capítulo XXXVIII del libro III, podemos leer la

brado; / que así el imperio consigue / altos reyes, porque todos, / por llegar a preferirse / a sus hermanos, se crían / magnánimos y sutiles, / doctos en ciencias y en armas, / sin que ley tan sola olvide / las hembras, pues no lo es / que el ser mujeres nos quite / la acción de reinar» (vv. 177-195). 
descripción de la batalla decisiva entre los griegos y los tártaros en Constantinopla, cuya extensión es de ¡36 páginas! Las violentas imágenes que aparecen en la novela tienen características distintas a las presentadas en el lenguaje teatral. El lenguaje narrativo permite el uso de más detalles descriptivos. Además, la exageración —la hipérbolede las acciones guerreras en los romances de caballerías mantenía a la imagen cruenta en la superficie misma de toda la narración. Veamos un ejemplo:

Como el encuentro de estos seis caballeros fue hecho, luego las dos haces fueron juntas.Y fueron tantos los muertos que cayeron de una parte y de otra, que ya los vivos no podían pasar sino por encima de ellos. $\mathrm{Y}$ con el polvo que levantaron, ninguna cosa casi se veía sino los muchos caballos y elefantes que salían sueltos de la prisa. Y ciertamente era cosa de gran lástima oír los gritos que daban los heridos; que muchos de ellos que pudieran sanar, sin se poder levantar recibían muy triste y desesperada muerte entre los pies de los caballos. (p.101)

De modo que Calderón trabaja con este material novelesco para la concepción de su obra, adaptándolo a los espectadores del siglo XVII, quienes con seguridad conocían esa fábula aunque quizá ya no la hubieran leído, pues las novelas de caballería habían pasado de moda. En ese proceso de reescritura, don Pedro selecciona el material conveniente y reestructura con nuevos hilos la tensión dramática. Los versos en voz de Lindabridis describen la guerra ocurrida en un tiempo anterior al inicio de la obra. Explica el porqué Lindabridis se ve forzada a recorrer el mundo en búsqueda de los mejores caballeros para que alguno pueda vencer a su hermano. Calderón deja así una nota del pre-ambiente violento que justifica las acciones y el final de la comedia.

En efecto, desde un enfoque teatral, el cierre de toda obra es el elemento básico que da sentido al conjunto de la representación, se va construyendo por medio de cada acción escénica desde el principio. Como señala el investigador Isaac Benabu:

"In the end is the beginning». By this I mean that an analysis of the playtext, read theatrically, necessarily turns to the point at which complication is resolved, the ending, where the faultiness of character and plot reveal themselves at their fullest, so as to gather firm evidence for the 
construction of that opening, and in order to ascertain at what point to pitch the opening ${ }^{7}$.

La lectura teatral de una obra, aquella dirigida a la representación, evoluciona y toma forma en relación directa con el final del espectáculo. En la obra de El castillo, el gran cierre es la escena del torneo (que resolverá el conflicto en vez de la guerra civil del inicio). En la novela de Ortúñez, una de las características más llamativas de los torneos es la cualidad de lo espectacular. A diferencia de las grandes guerras donde combaten todos los miembros de los ejércitos involucrados o los menores encuentros bélicos fortuitos, en los torneos debe haber una preparación para el evento, un preámbulo en que tanto contrincantes como espectadores se disponen a asumir el rol que les corresponde. Uno de estos torneos lo encontramos descrito en el capítulo XXX del libro III; en él se enfrentan una comitiva de cada ejército (griegos y tártaros) de 15 caballeros. El duelo total es narrado en 10 páginas, describiendo uno a uno los combates de cada grupo. Desde el principio vemos los preparativos necesarios para dicha escena, abriéndose el capítulo con estas palabras:

Venido el día del desafio, en que había de hacerse la batalla entre los quince caballeros del emperador Trebacio y los otros quince del emperador Alicandro, todos fueron puestos muy a punto, y el campo donde había de ser la batalla fue señalado en medio de los dos ejércitos, cerca de la gran ciudad, de manera que se podía muy bien mirar de las ventanas del palacio del emperador que caían sobre las cercas hacia aquella parte. (p. 7)

El párrafo nos permite también percibir la diferenciación de espacios, pues se designa el espacio del combate separado de aquel de los espectadores. La alusión al atractivo visual de la pelea es constante en la narración: «y era cosa muy digna de mirar ver los golpes que se daban y la herrería que traían» (p. 15). El espectáculo consiste, pues, en la calidad de la lucha que ofrecen los contrincantes a los que observan la batalla desde lejos. En el duelo de El castillo, aunque descrito someramente por las acotaciones, se puede percibir la magnitud del espectáculo contenido en esas líneas. La primera seña es dada por el

7 Benabu, 2003, p. 81. 
diálogo de Malandrín, el gracioso, quien se queja de no tener un buen lugar para ver el encuentro:

\author{
¡Oh quién tuviera boleta \\ para ver de una ventana \\ toda la fiesta! Aunque a mí \\ muy poco de ver me falta. (vv. 3399-3402)
}

El parlamento siguiente, donde el mismo personaje describe a todos los contrincantes y sus emblemáticos escudos, nos introduce al ambiente del desfile previo al combate y a los adornos que sirven para definir el espacio de lucha, la estacada, y mostrar el rango del evento ${ }^{8}$. Aunque en la escena del torneo el diálogo es muy breve, hay dos acotaciones que describen la acción. Una lectura literal de ellas construiría un final artificial y poco contundente, de ahí que el enfoque teatral sea tan necesario. La primera acotación dice así:

Descúbrese el rey Licanor en un trono; sale Meridián de su tienda, y hacen la entrada por el palenque Febo, Floriseo, el Fauno, Rosicler, Claridiana y Lindabridis, todos con armas, $y$ delante criados con los escudos, como han dicho los versos; y, en llegando delante de Licanor, hacen reverencia y ocupan sus puestos.

«La entrada por el palenque» es la clave para visualizar el grandioso desfile de los participantes. Esta palabra puede hacer alusión a dos realidades distintas, pero que, a través de la magia teatral pueden significar la misma cosa. Palenque, según el Diccionario de Autoridades, podía ser entendido como «la valla o estacada que se hace para cerrar algún terreno; en que ha de haber lid, torneo u otra fiesta pública...»" acepción que encaja perfectamente con la situación dramática de la obra, pues los contendientes se preparan para iniciar el torneo. Así también, el segundo significado alude a «un camino de tablas, que desde el sue-

8 «En efecto, / amaneció esta mañana / cubierto el sitio de tiendas / de damasco, tela y grana; / era un monte levadizo / que, para engañar al alba, / nieve y flores le vestían / las plumas sobre las armas. / Listadas de azul y oro / se vieron todas las vallas, / que presumió el sol que era / la eclíptica que él abrasa. / No la hicieron salva, no, / los músicos que la aguardan; / que otros pájaros canoros / de metal la hicieron salva» (vv. 3423-3438).

${ }^{9} \mathrm{Voz}$ «palenque», t. 5 , p. 90. 
lo se eleva hasta el tablado de las comedias, cuando hay entrada de torneo u otra función semejante». De modo que designa un accesorio teatral específico. Podríamos leer la frase como una nota de dirección escénica que contribuye a la espectacularidad de la secuen$\mathrm{cia}^{10}$.

Las acciones exactas no son mencionadas, pero, a pesar del vertiginoso diálogo, uno puede adivinar una coreografia congruente al momento escénico. La segunda acotación, mucho más breve, recrea el suspenso previo al inicio del combate: "Repártense a un lado Lindabridis, Claridiana y Meridián; a otro Rosicler, Febo y Floriseo, y el Fauno en medio». En seguida, después de una línea de diálogo ${ }^{11}$, la tercera acotación señala el movimiento final de la secuencia, es decir, el triunfo de Claridiana sobre los demás: «Llega Claridiana y derriba el Fauno a sus pies». Los movimientos escénicos y la coreografía no están definidos por la obra, solo el final del combate, el cual permite a Calderón restituir el orden y acabar con el final feliz esperado, apenas 28 versos después de la caída del Fauno. Claridiana es la vencedora del torneo no por el uso de la fuerza o la destreza guerrera, sino por el encantamiento del amor, aspecto que toma más resonancia cuando se analiza con el resto de la obra. El Fauno es vencido entonces por una fuerza mucho más poderosa y a la que finalmente todos debemos cierto vasallaje.

Ahora bien, la naturaleza deíctica del teatro cuestiona las posibilidades actuales de realización escénica. Si enfocamos la atención en estas dos secuencias, se levanta la pregunta sobre la manera de representar la violencia en escena. Sin olvidar además, que se trata de una comedia de efecto irrisorio, es decir, una "obra dramática cómica» según la división que Ignacio Arellano propone en su libro sobre la convención y la recepción del teatro barroco ${ }^{12}$. Dado que el ambiente caótico previo a la acción de la obra es necesario para entender las peripecias del drama, hemos planteado la posibilidad de iniciar la obra

10 Es posible que el «palenque» teatral hubiera sido más usado en los corrales ya que se habla en la definición de tablado y no de escenario, término con que fue conocida el área escénica del teatro a la italiana. De todas formas, incita la posibilidad de imaginar dicha entrada aún en un espacio a la italiana como lo hubiera sido el Coliseo del Buen Retiro, causando un sorprendente entretenimiento para los asistentes de la comedia.

11 «La victoria está por mía» (v. 3581).

12 Arellano, 1999. 
con la proyección de las imágenes de la guerra tártara, a modo de opertura. Y para mantener la estética elegida de la puesta en escena, el videograma sería realizado con el lenguaje del comic. No es lugar aquí para extender las explicaciones sobre la influencia de este arte en la cultura popular actual, digamos solo que sus posibilidades expresivas, sobre todo en torno a la violencia, son herramientas de gran utilidad para nuestro proyecto. Ya en los corrales, la tecnología ayudaba en la presentación de escenas violentas, como indica Ruano de la Haza en su libro sobre los corrales comerciales: «Muchas apariencias presentan cruentas escenas de sacrificios y torturas, que por razones obvias no podían representarse sobre el tablado» ${ }^{13}$. Así, nosotros hacemos uso de la proyección y de las calidades técnicas de los dibujos animados para nuestro propósito.

A esto se añade el imaginario del espectador contemporáneo que ya incluye una serie de predisposiciones para decodificar la información que se le muestra. Las percepciones del público del siglo XxI, los nuevos lenguajes escénicos y la sociedad tecnologizada en la que vivimos, exigen un tratamiento distinto de nuestros textos clásicos. El duelo a muerte tendría que ser ejecutado por los actores a manera de coreografia de combate, ayudada de la creatividad y el arte tecnológico (especialmente en este caso del sonido y las imágenes en directo). El ambiente sonoro es uno de los aspectos más presentes en las descripciones bélicas de la novela. A manera de soundtrack o banda sonora, los párrafos ambientales acompañan la descripción de las acciones:

De esta manera era la batalla entre todos ellos la más bien reñida y golpeada que jamás se vio de tantos caballeros; que todos los que la miraban parecían tener los oídos atronados con el continuo resonar de los duros y espesos golpes que se daban. Que no hubiera más ruido si cien herreros estuvieran allí juntos martillando. (cap. XXX, p. 17)

Observamos pues, que la escena tecnológica actual ofrece nuevas herramientas para la interpretación de la obra, pero han de usarse sin quebrar la armonía de la escenificación integral. El sonido, las imágenes de fondo y las pantallas, el uso de cámaras en directo, todos los recursos trabajan a un tiempo —en conjunto con actores, verso, músi-

${ }^{13}$ Ruano de la Haza, 2000, p. 229. 
ca o vestuario-, en el mismo sistema de representación para mantener ese equilibrio que también buscaba Calderón en sus obras de espectáculo al incluir todas las artes y técnicas disponibles, para la conformación de un teatro total. 


\section{Bibliografía}

Arellano, I., Historia del teatro Español del siglo XVII, Madrid, Cátedra, 1995.

- Convención y recepción: Estudios sobre el teatro del Siglo de Oro, Madrid, Gredos, 1999.

Benabu, I., Reading for the stage: Calderon and his contemporaries, Woodbridge, Tamesis, 2003.

Calderón de la Barca, P., Comedias, ed. J. J. Keil, Leipzig, 1830. http://www.coh.arizona.edu/spanish/comedia/calderon/escaslin.html

- El castillo de Lindabridis, ed. V. B. Torres, Pamplona, EunsA, 1987.

- Novena parte de comedias (Madrid, 1691), ed. facsímil D. W. Cruickshank y J. E. Varey, London, Tamesis, 1973.

- Obras completas, ed. Á. Valbuena Briones, Madrid, Aguilar, 1959.

Cotarelo y Mori, E., Ensayo sobre la vida y obras de Don Pedro Calderón de la Barca (1924), ed. facsímil I. Arellano y J. M. Escudero, Madrid, Iberoamericana / Vervuert, 2001.

Diccionario de Autoridades (1726), ed. Real Academia Española, Madrid, Editorial Gredos, 1964, 3 vols.

Ortúñez de Calahorra, D., Espejo de príncipes y caballeros [El caballero del Febo], ed. D. Eisenberg, Madrid, Espasa Calpe, 1975.

Rodríguez Cuadros, E., Calderón heterogéneo, Calderón heterodoxo, 2000. http://www.cervantesvirtual.com/bib_autor/calderon/autor2.shtml

- Calderón y su época, 2000. http://www.cervantesvirtual.com/bib_autor/calderon/autor.shtml

Ruano de la Haza, J. M., La puesta en escena en los teatros comerciales del Siglo de Oro, Madrid, Castalia, 2000.

Rubiera Fernández, J., La construcción del espacio en la Comedia española del Siglo de Oro, Madrid, Arco/Libros, 2005. 